\title{
Connecting Through Technology During COVID-19
}

Jeffrey A. Hall ${ }^{1}$, Natalie Pennington ${ }^{2}$, and Amanda J. Holmstrom ${ }^{3}$

${ }^{1}$ The University of Kansas, ${ }^{2}$ University of Nevada, Las Vegas, ${ }^{3}$ Michigan State University

From the rise of the internet to contemporary advances in wireless mobile technology, information and communication technologies (ICTs) have transformed and broadened the available modes of interpersonal communication (Hall, 2020). In the spring of 2020, shelter-in-place (SIP) orders necessitated by the COVID-19 pandemic dramatically reduced opportunities for face-to-face ( $\mathrm{FtF}$ ) communication with others outside of the home (Andrews, 2020). As a result, for most of the developed world, mediated communication became the primary way to keep in touch (Pew Research Center, 2020a). These unprecedented circumstances created a case study of how ICTs bridge the gap between those under SIP orders and friends and family residing elsewhere, providing evidence as to whether doing so might alleviate stress and loneliness and help individuals get their social needs met.

Drawing from media richness theory (MRT; Daft \& Lengel, 1984) and the interplay between FtF and online communication (Hall, 2020), this study explores whether modality usage is associated with Americans' abilities to psychologically and socially cope with the dramatic reduction of routine $\mathrm{FtF}$ communication outside of the home. In documenting the patterns of ICT use with friends and family outside of the home and exploring the associations among various modalities and respondents' psychological (i.e., loneliness; stress) and social outcomes (i.e., social needs; relationship maintenance difficulty), this manuscript offers a rich and complex account of the role ICTs played during the SIP period of the COVID-19 pandemic (i.e., March-May, 2020).

\section{Media Richness Theory (MRT)}

Developed in a time of text-focused, low-synchrony ICT use, MRT (Daft \& Lengel, 1984) argues the degree of nonverbal immediacy is the causal agent when determining whether people can build relationships through technology. From MRT's perspective, a modality's richness is its carrying capacity, which includes the amount of nonverbal cues, the use of spoken language, and synchrony (Daft \& Lengel, 1984). The theory presumes under conditions of low social cues, interaction partners will experience less warmth, empathy, and friendliness (Daft \& Lengel, 1984). This is due to the presumptive role of social presence in influencing communication outcomes. Social presence can be defined as "states of awareness of the self and other" (Walther, 2011, p. 446). According to MRT, social presence 
is the highest when people interact FtF and decreases as social cues are reduced. Although there is some consensus that social presence varies in important and salient ways by modality (Baym, 2015; Walther, 2011), it does not appear to be strictly a function of fewer nonverbal channels. This is likely because people re-introduce cues through textual features, emojis and memes, and photos (Tong \& Walther, 2015; Walther, 2010). That is, people artfully and intentionally use the features of the modality to convey whatever meaning they wish-aggression or support, humor or formality (Baym, 2015). Thus, text-only communication is more than sufficient in conveying impressions and building affinity (Tong \& Walther, 2015; Walther, 2010).

Predictions derived from MRT have shown more support in the domain of task accomplishment in comparison to relational contexts (Baym, 2015; Walther, 2011). While the primary outcomes of the theory (e.g., efficiency) are often viewed as more pertinent to organizational settings than interpersonal ones, MRT remains valuable in describing differences between modalities and predicting their effects (Walther, 2011). In considering the role of ICTs compared to FtF interactions during the pandemic, MRT may be useful in assessing key differences and similarities across modalities in regard to getting one's social needs met and reducing stress and loneliness.

\section{Social Ecology and Social Interaction}

Although no single theoretical perspective has emerged to understand how media and FtF communication function in tandem, Baym's key concepts (2015), the communication interdependence perspective (Caughlin \& Sharabi, 2013), and need-motivation theories (Sheldon et al., 2011) have all added insight that can build on earlier MRT theorizing regarding differences across modalities. Hall's (2020) social ecology perspective integrates these perspectives in four components: 1) individuals have an innate need to belong that can be satisfied through social behaviors, including mediated communication; 2) routine FtF interaction accounts for the majority of individuals' social lives; 3 ) the presence of and access to relational partners plays a key role in explaining ICT use; and 4) social interactions vary in their ability to satisfy belongingness needs, both in content and modality. Drawing from well-established models of social need satisfaction (e.g., Leary \& Kelly, 2008; Sheldon et al., 2011), Hall (2020) argues that when individuals experience unmet social needs, they seek social interaction. Because the need to feel close and connected to others is innate (Leary \& Kelly, 2008), successfully getting one's social needs met is a critical part of human thriving. Both the quality and quantity of social interactions are well-documented predictors of loneliness and global well-being (Hall \& Merolla, 2020; Pinquart \& Sorensen, 2003). In this way, MRT aligns well to consider how richer versus leaner mediums may facilitate a greater quality of interaction and promote need satisfaction.

Although research has often focused on ICT use in isolation, Hall (2020) argues that most relationships, especially close relationships, are multi-modal and social uses of media should be understood in conjunction with FtF interaction. Prior to the pandemic, roughly two-thirds of Americans' social interactions took place FtF (Hall, 2020). Daily FtF social interactions (e.g., at work, school, home) are critical components of human social ecology because such interactions are routine, famil- 
iar, and obligatory. Thus, the presence or absence of important relational partners - both physically and in a relational sense - play a key role in whether people get their social needs met and when and why they use ICTs.

Past studies have also consistently found routine FtF access increases (and a lack of FtF access decreases) the formation and maintenance of relationships (Hall, 2020). Once people no longer share FtF routines, they must compensate for a lack of access by using the modalities available to them and to their relational partners. In the past, posted letters and telephone calls served that function (Fischer, 1992). At the turn of the century, email and texting became widely available, followed by video chat, social media, and online gaming. Despite an increase in modality choice, keeping in touch through media is still proportionally rare both in frequency and in number of partners. One estimate (e.g., Tillema et al., 2010) suggests only $2-6 \%$ of people were in daily ICT contact with their closest friends and family who lived outside of the home. Furthermore, it is a well-established pattern of ICT use that closer relationship partners communicate through multiple modalities (Baym, 2015; Caughlin \& Sharabi, 2013). Therefore, if mediated interactions with people who live together (e.g., cohabitating romantic partners) or see each other routinely (e.g., friends at school/ work colleagues) were removed from the total amount of mediated communication in a day, only a tiny portion of personal media use would be with people who do not also have routine FtF contact.

The social ecology perspective suggests social interactions must be considered in conjunction with access to relational partners. For example, having a partner at home decreases communication with others outside of the home, and making a new close relationship decreases the amount of communication with old relationship partners (van den Berg et al., 2012). By extension, the lack of partners at home (i.e., being single or living alone) increases communication outside of the home, including both FtF and through ICTs (Sarkisian \& Gerstel, 2016). Taking the social ecology perspective on relationships and satisfaction together in conjunction with MRT can help to understand how individuals meet their needs for connection during the pandemic.

\section{Sociality During COVID Shelter-in-Place}

Faced with the dire threat of COVID-19, world leaders turned to SIP orders to control rates of infection. By early May 2020, the week of data collection for this study, most Americans had already endured weeks of sheltering in place, and were desperate for social connection with friends, family, and members of their communities (Moore et al., 2020). As SIP orders greatly diminished opportunities for interaction with people outside of the home, people became more reliant on ICTs to socialize. In April of 2020, the number of daily voice calls was twice that of the peak traffic day in 2019 (Minium, 2020). In the month of March, all video chat platforms saw increased use while Zoom video chat quadrupled with little sign of slowing (Koeze \& Popper, 2020). As people found themselves near home computers, internet access to Facebook was also up 27\% in the first four weeks of the virus (Koeze \& Popper, 2020). We explore these trends in the present study through the following research question: 
RQ1: What modalities are people using during the pandemic to keep in touch with friends and family outside of the home, people at work, and those within the home?

In line with the social ecology perspective, interactions with close relationship partners are an important source of getting one's social needs met and mitigating loneliness (Hall \& Merolla, 2020), however, interactions with weak ties are also important (Sanderson \& Dunn, 2014). In addition, close partners (i.e., parents, children, romantic partners, friends) may not necessarily share the same residence. Similarly, in line with MRT, FtF communication is considered "the gold standard" for communication as it is the richest (Walther, 2011). For those who live alone, the SIP orders likely created a particularly deprived social environment. Thus, we expect three structural factors to play a role in psychological and social well-being:

H1: Individuals with less routine FtF access to others (i.e., SIP, living alone, not in a romantic relationship) will experience poorer psychological (i.e., loneliness, stress) and social (i.e., getting social needs met, ease of relationship maintenance) health.

\section{Media Choice and Social Needs}

The final component of Hall's (2020) social ecology model suggests social interactions are not equal in their ability to meet people's needs, and modalities differ in their ability to satisfy needs. We next discuss associations between the following modalities and need satisfaction: FtF communication, voice calls, texting, video chat, social media, email, and online gaming.

FtF communication. There is good evidence FtF communication stands apart from all other modalities. Using an experimental framework, Sprecher (2014) found initial interactions in which FtF resulted in higher liking, closeness, responsiveness, and enjoyment than either video chat or voice calls, which, in turn, were rated higher than text-only exchanges. Frequency of FtF contact has been more strongly associated with subjective well-being than contact by phone or internet (van der Horst \& Coffe, 2012), and FtF interactions with friends and family predict increased life satisfaction and lower loneliness, but email and other internet-based modalities show no such positive effects (Stepanikova et al., 2010). Some researchers (e.g., Vlahovic et al., 2012) have argued FtF is empirically distinct from all other forms of communication. Furthermore, $\mathrm{FtF}$ is perceived as more adaptable to a wide range of emotions, communication goals, and relationship partners. It is still considered the best form of communication by $83 \%$ of young adults (Duran \& Kelly, 2017; Eden \& Veksler, 2016).

Voice calls. According to MRT, voice calls more closely approximate FtF interaction, and are perceived as important means of replacing lost FtF contact (Fischer, 1992; Ruppel \& Burke, 2015). A recent meta-analysis (e.g., Liu et al., 2019) reported the frequency of voice calls was positively associated with well-being $(k=9, r=.10)$. However, these findings may be conflating partner choice with modality; people typically reserve high social cue media for communication with close others (Hall, 2020; Liu et al., 2019). Using an experience sampling framework that controlled for variance explained by partner closeness, however, Hall (2020) reported voice calls were similar to $\mathrm{FtF}$ communication in terms of momentary affective well-being and connection, and lower levels of in-the-moment loneliness. 
Texting. Texting frequency is also positively associated with global well-being $(k=9, r=.10)$ (Liu et al., 2019). Cross-sectional research comparing FtF communication to text, however, has found FtF contact was more capable than text of meeting individuals' needs for inclusion and closeness (Liu \& Yang, 2016). In initial interactions between strangers, FtF contact was more likely to meet the need to build intimacy (Sprecher, 2014). Controlling for partner closeness, Hall (2020) reports FtF communication still showed a greater degree of connection and well-being and less loneliness than texting (see also Vlahovic et al., 2012). Based on the past work supporting the value of FtF, voice calls, and texting, the following hypothesis was posed:

H2: FtF, voice calls, and texting with friends and family the outside home will be associated with less loneliness, more getting social needs met, less relationship maintenance difficulty, and less stress.

Video chat. According to MRT, like voice calls, video chat programs more closely approximate FtF interaction (Fischer, 1992; Ruppel \& Burke, 2015). While it also approximated FtF communication in terms of connection and affective well-being, Hall's (2020) study using experience sampling found that video chat was associated with higher degrees of loneliness than FtF communication or voice calls (Hall, 2020). Paradoxically, the heightened cue environment might render what is missing more salient (e.g., touch). It is consistent with this paradox that the sense of something missing is often experienced in long-distance romantic relationships (Neustaedter \& Greenberg, 2012), but not among new acquaintances (Sprecher, 2014). Seeing a missed loved one on a screen might be a potent reminder of missing that person's physical presence (Hall, 2020).

Social media. In contrast to more traditional modalities (e.g., voice calls), social media has received nearly 10 times the amount of research attention $(k=94)$ in terms of its association with well-being (Lui et al., 2019). The type of social media use, direct messaging or chatting through social media (interactive) versus browsing or passive use (consumptive), appears to moderate that relationship: interactive forms of use positively predict $(r=.14)$ while consumptive forms negatively predict $(r=-.14)$ well-being (Lui et al., 2019). Outside of the context of a back-and-forth social interaction, social media also does not appear to satiate belongingness or relatedness needs (Reinecke et al., 2014). Recent work on social media use during the pandemic points to excessive use as contributing to feelings of depression, while also identifying the potential for support to be gained from one's network (Zhong et al., 2020).

Email. Although once a primary tool for keeping in touch (Hall, 2020), email appears to be dropping off as means of relationship maintenance. Ten years ago, $14 \%$ of people chose email as a mechanism to discuss important matters with close friends and family (Tillema et al., 2010). More than any other textual medium, email is reserved for composing long, in-depth messages, akin to posted letters, which offer the opportunity to be re-read and even savored by relational partners (Hall, 2020). Indeed, email appears to be a complementary part of keeping in touch with long-distance friends (Ruppel \& Burke, 2015).

Online gaming. A recent meta-analysis (e.g., Lui et al., 2019) shows the relationship between well-being and online gaming is no different from zero, although the association was trending negative $(r=-.12, k=7)$. A longitudinal study of gaming 
(e.g., Domahidi et al., 2018) concluded that gaming related friendships do not impact social outcomes, but gaming may be a means of bonding with close friends by increasing time spent together.

In comparison to findings related to FtF communication, voice calls, and texting, research on the benefits of video chat, social media use, email, and online gaming are inconclusive. Given these inconsistencies in the literature, the following research question was posed:

RQ2: What is the association between video chat, social media use, email, and online gaming with friends and family outside of the home and loneliness, getting social needs met, relationship maintenance difficulty, and stress?

\section{Moderating Effects of Structural Circumstances}

Whether living alone or with others, to replace those lost social opportunities, people turned to media of various sorts to keep in touch during the pandemic. We expect that structural circumstances (i.e., living alone, being single, SIP) may place individuals at higher risk of negative outcomes (i.e., H1). These factors also may influence the efficacy of the modality for keeping in touch. Hall (2020) suggests that the absence of routine communication partners may make the influence of high richness modalities more salient, while the efficacy of leaner modalities may be lessened when routine interactions are absent. When people are at high states of social need, a voice call may help to alleviate loneliness (Hall, 2020), but social media use might not (Sheldon et al., 2011; Reinecke et al., 2014; Zhong et al., 2020). Therefore, we pose:

RQ3: Are the effects of each modality (FtF, voice call, texting, video chat, social media use, email, and online gaming) moderated by relationship status, living alone, and SIP?

Data collected in April from the Pew Research Center (2020a) suggests that young adults and college graduates are most likely to use ICTs for socializing. Older Americans (> 65) may have a discomfort or unfamiliarity with how to properly use ICTs, leading to a lack of mediated social interactions (Pew Research Center, 2020b). However, older Americans may be more familiar with voice calls and email (Minium, 2020), which may be advantageous during the SIP period. Thus, we query:

RQ4: Are the effects of each modality (FtF, voice call, texting, video chat, social media use, email, and online gaming) moderated by age?

\section{Methods}

\section{Procedures and Participants}

Procedures. On May 11 and 12, 2020, we commissioned a representative panel of American adults from the Siena College Research Institute (SCRI) and the panel company, Lucid. Participants were recruited to form a quota sample of age, sex, political affiliation, region of the country, and race and ethnicity. All measures were completed via an online survey, and participants were compensated by Lucid, consistent with the terms of their agreement. These procedures were approved by the IRBs of the authors' universities.

SCRI administered an attention check item and removed all respondents who 
failed it. We took additional steps to remove suspect data: rank order questions completed incorrectly, survey completion in less than three minutes or more than three standard deviations above the mean, and meaningless responses to open-ended questions. Participants with two or more suspicious responses $(n=$ 55) were removed, leaving a final sample of $(N=1,947)$.

Participants. Of the final sample, $51.6 \%$ identified as female, $47.6 \%$ as male, and $.9 \%$ identified as transgendered male or female, non-binary, or by filling in an "other" category. The mean age of participants was 46.5 years old (range $=18-92$ ). Participants identified as many race and ethnicity categories as they wished: 75\% identified as White, $11.4 \%$ as Black/African-American, $9.4 \%$ as Latino/Hispanic, $6.1 \%$ as Asian-American, $1.3 \%$ as Native-American, .2\% as Pacific Islander, and $.8 \%$ identified as "other" race or ethnicity. The median household income was $\$ 60-70 \mathrm{~K}$ per year, and there was a bimodal distribution in income: $\$ 30-39 \mathrm{~K}(11.3 \%)$ and $\$ 100-120 \mathrm{~K}(12 \%)$. The modal level of education was high school graduate, and $12.5 \%$ were currently enrolled in an associates or bachelor's degree education. Participants were primarily married or engaged (44\%) or single $(40 \%)$, with fewer in a committed dating relationship (12\%) or identifying as widowed, separated, or divorced (4\%). The number of members of the household varied: $19 \%$ lived alone, $26 \%$ with another person, $22 \%$ with two others, and the remaining $33 \%$ had four or more members of their household. More than a third (36\%) had children under 18 at home, and $17 \%$ had other dependents in their homes (e.g., sick or elderly family members). Finally, 50\% were employed and, of that group, $45 \%$ worked outside of the home during SIP orders. Of those who were not currently employed, $10 \%$ were full-time students, $17 \%$ had lost their jobs because of COVID-19, and others were retired or full-time caregivers.

To facilitate data analyses, dummy coding was used. Self-identified sex was coded in three categories. Participants who reported being Latino/Hispanic were coded separately from race. Participants who reported more than one race were coded as mixed race. Participants who were married, dating, or engaged were coded as presently being in a romantic relationship compared to presently single (i.e., separated, divorced, widowed, single). Participants who lived alone were dummy coded. At the point of data collection (May 11-12, 2020), participants were asked to identify how many weeks they had been SIP (defined as only leaving the house for certain activities (i.e., groceries, curbside pickup, walking around outside, or work). Ninety-two percent of participants reported having been SIP during some period of the pandemic, and $90 \%$ were currently SIP. A minority of respondents $(10 \%)$ were going about their normal routine without SIP. Of those engaging in SIP, $68.1 \%$ stated it was state mandated, with the remaining indicating it was an individual choice.

\section{Measures}

After consenting and completing demographic measures, participants responded to items focusing on social and psychological needs. Four one-item measures of outcomes were used in the survey. Loneliness was measured with one item from the Social Functioning Questionnaire: "How often have you felt lonely and isolated from other people in the past week?"; Stress was measured using an item from PROMIS Emotional Distress: "stress means a situation in which a person 
feels tense, restless, nervous, or anxious or is unable to sleep at night because their mind is troubled all the time. How often have you felt this kind of stress in the last week?" Social needs were measured using an item developed for this study: "In the past week, how often have you felt like you were getting the amount of social contact that you need?" Relationship maintenance difficulties was measured an item from Ryff \& Keyes' (1995) scale: "In the past week, how often has it been difficult or frustrating to maintain your close relationships?" Reponses were given on a five-point scale (Never, Rarely, Occasionally, Often, All of the time).

There were three blocks of items corresponding to social relationships (a) outside of home, (b) at work, and (c) at home. In the first block, participants responded to the prompt: "We'd first like for you to consider the people who live outside your house that you have been keeping in touch with. These are NOT people who you must speak to because of your job or for school. In the past week, have you been in contact with anyone who meets this description?" Overall, 76\% of participants indicated they had been keeping in touch with people outside their house. In the second block, we asked participants whether they had been in contact with people at work, and 38\% indicated they had been in contact. Finally, participants who indicated that they did not live alone $(81 \%)$ were asked questions about the people they lived with.

Participants were asked about their ICT use for each context they indicated that they had communicated in within the last month (i.e., work, friends, within the house). There were 10 options for modality of communication: FtF, email, telephone, video chat, texting, social media browsing, social media posting, social media direct messaging, online gaming, and engaging with online communities. Social media use was broken into three possible types of engagement based on past literature exploring how types of use relate to well-being. Participants were asked to indicate if they used that modality in the last week (yes/no), and then

Table 1. Frequencies and Mean Rank Order of Modality by Communication Group

\begin{tabular}{|c|c|c|c|c|c|c|}
\hline & \multicolumn{2}{|c|}{$\frac{\text { Outside Home }}{N=1475}$} & \multicolumn{2}{|c|}{$\frac{\text { Work }}{N=745}$} & \multicolumn{2}{|c|}{ Inside Home } \\
\hline & $\underline{\%}$ & Rank & $\underline{\%}$ & Rank & $\underline{\%}$ & $\underline{\text { Rank }}$ \\
\hline Voice call & .91 & 2.55 & .77 & 2.71 & .64 & 2.75 \\
\hline Texting & .90 & $2.43^{\mathrm{a}}$ & .80 & $2.69^{a}$ & .73 & 2.64 \\
\hline Social media browsing & .64 & 4.66 & .45 & 4.70 & .38 & 4.68 \\
\hline Email & .62 & 3.64 & .69 & 2.71 & .32 & 3.96 \\
\hline Video chat & .60 & 3.56 & .53 & 3.21 & .30 & 3.63 \\
\hline Face- & .57 & 3.96 & .54 & 3.01 & .90 & $1.65^{a}$ \\
\hline Social media DM & .56 & 3.97 & .46 & 3.86 & .34 & 4.23 \\
\hline $\begin{array}{l}\text { Social media posting/ } \\
\text { commenting/sharing }\end{array}$ & .56 & 4.54 & .41 & 4.54 & .34 & 4.67 \\
\hline Online communities & .36 & 6.36 & .30 & $6.23^{b}$ & .21 & $6.50^{\mathrm{b}}$ \\
\hline Online gaming & .31 & $6.37^{b}$ & .26 & 5.85 & .24 & 5.59 \\
\hline
\end{tabular}

Notes. Higher ranking is closer to $1,^{a}=$ highest rank, ${ }^{b}=$ lowest rank within each context 
asked to rank order the modalities "from the one you used the most to the one you used the least in the last week to keep in touch with this group of people."

\section{Results}

To answer RQ1, we calculated the percentage of respondents who used each modality and the mean rank order (Table 1). Results suggested that voice calls and texting were the most frequently used and the most important (i.e., highest ranked) modalities that people used during the pandemic - whether with friends and family outside the home, at work, or between people who cohabitate. Social media were more frequently used among friends and family outside of the house, email for work colleagues, and FtF communication among people who live together.

In addition to exploring overall rank order and mean usage (Table 1), we ran bivariate correlations among modality use $(\mathrm{Y} / \mathrm{N})$ and psychological and social outcomes for communication outside the home (Table 2). Of particular note, FtF communication and voice calls were associated with less loneliness both in use (Yes/No) and rank order, while all forms of social media use (i.e., DM, browsing, sharing), video chat, and gaming were associated with greater loneliness. FtF communication outside of the home (i.e., use, rank) was associated with getting one's social needs met $(r=.11, p<.01)$. Greater relationship maintenance challenges were associated with most forms of media use with video chat causing the most difficulty $(r=.12, p<.01)$; voice calls, texting, and email were the only modalities

Table 2. Bivariate Correlations among Outside Home Modality and Psychological and Social Outcomes $(\mathrm{N}=1475)$

\begin{tabular}{|c|c|c|c|c|c|c|c|c|}
\hline & Lon & liness & $\begin{array}{r}\text { Sc } \\
\text { Neec }\end{array}$ & $\begin{array}{l}\text { Met } \\
\text { Mel }\end{array}$ & $\begin{array}{l}\text { Maint } \\
\text { Diffi }\end{array}$ & $\begin{array}{l}\text { hance } \\
\text { lties }\end{array}$ & Stre & \\
\hline & $\underline{\mathrm{Y} / \mathrm{N}}$ & Rank & $\underline{\mathrm{Y} / \mathrm{N}}$ & $\underline{\text { Rank }}$ & $\underline{\mathrm{Y} / \mathrm{N}}$ & Rank & $\underline{\mathrm{Y} / \mathrm{N}}$ & Rank \\
\hline Voice call & $\overline{-.07}$ & $\overline{-.11}$ & $\overline{.01}$ & $\overline{-.00}$ & $\overline{-.04}$ & $\overline{-.07}$ & $\overline{-.08}$ & $\overline{-.12}$ \\
\hline Texting & .05 & -.06 & -.04 & -.04 & .06 & .06 & .10 & -.02 \\
\hline $\begin{array}{l}\text { Social media } \\
\text { browsing }\end{array}$ & .10 & -.00 & -.02 & -.04 & .07 & -.02 & .11 & .03 \\
\hline Email & -.06 & -.04 & .03 & .04 & .01 & .00 & -.03 & -.08 \\
\hline Video chat & .10 & .02 & .00 & .01 & .12 & .07 & .11 & -.02 \\
\hline Face-to-face & -.08 & -.09 & .11 & .14 & -.08 & .05 & -.04 & -.09 \\
\hline Social media DM & .11 & .03 & -.03 & .07 & .07 & .01 & .14 & .06 \\
\hline $\begin{array}{l}\text { Social media posting/ } \\
\text { commenting/sharing }\end{array}$ & .11 & -.01 & -.03 & .05 & .07 & .04 & .15 & .04 \\
\hline Online communities & .06 & .06 & .03 & .01 & .07 & .05 & .10 & .06 \\
\hline Online gaming & .10 & .07 & .04 & .03 & .12 & -.04 & .12 & .05 \\
\hline Total \# of Modalities & .10 & & .01 & & .11 & & .14 & \\
\hline
\end{tabular}

Notes. Y/N responses; Positive correlations reflect a higher rank order (more important) of that modality; For rank order the number of observations only include those who use that modality; Bold $p<.01$ 
unrelated to maintenance challenges. Finally, stress was positively associated with the majority of modalities as well as the total number of modalities, but not email or FtF communication. Stress was negatively associated with voice calls $(r=-.08, p$ $<.01)$, and most strongly associated with social media posting/commenting/sharing $(r=.15, p<.01)$.

To test H1-H3 and answer RQ2, stepwise regression was used to examine whether these associations held up after accounting for the variance associated with demographic characteristics. Given the likelihood of multicollinearity and similar patterns of correlations reported on Table 2, two exploratory factor analyses (EFA) were conducted using promax rotation and principal axis factoring to determine if the social media items constituted a single factor. One EFA included the use $(\mathrm{Y} / \mathrm{N})$ and the second the rank order, and both suggested that social media behaviors constituted a single factor. As all other modalities were distinct from social media and different in form and function from the alternatives (Hall, 2020), no other modes of communication were submitted to factor analysis. OLS regression was first conducted using only demographic characteristics as predictors. Then, a stepwise regression was conducted for the modality use variables (Table 3).

Supporting H1, people who were in a romantic relationship reported less loneliness and stress, and they reported getting their social needs met and had fewer difficulties maintaining relationships. Being SIP had the opposite associations: more loneliness and stress, less getting needs met and more relationship maintenance challenges. Unexpectedly, living alone was unassociated with loneliness, social needs being met, and maintenance difficulties, but was associated with less stress (see Table 3).

In support of $\mathrm{H} 2, \mathrm{FtF}$ communication and voice calls were associated with less loneliness, while social media and online gaming (RQ2) were associated with greater loneliness. Additionally, email (RQ2) was associated with less loneliness, and video chat (RQ2) was associated with more loneliness. Also supporting H2, FtF communication predicted getting one's social needs met. Participants reported more relationship maintenance challenges when they reported more social media use and online gaming (RQ2), and less difficulties when they communicated FtF (H2). Finally, stress was predicted by more online gaming, texting, and social media use. Less stress was associated with FtF communication, email, and voice calls (H2, RQ2). Effect sizes suggested that modality usage explained a similar amount of variance in outcomes as demographic characteristics and living conditions.

\section{Moderation Analyses}

Moderation analyses using PROCESS (Hayes, 2018) were conducted to explore whether these associations were conditional upon structural relational characteristics (i.e., living alone, being single, SIP) and demographic characteristics (i.e., age). The patterns of results for voice call, video chat, and online gaming were consistent with the primary results. The effects of three modalities were moderated by structural characteristics (RQ3) or age (RQ4).

The first set of moderations explored FtF communication. The relationship between loneliness and FtF communication was approaching significance for a moderation by SIP, $B=.40, S E=.24, p=.097$, $\mathrm{LLCI}=-.07, \mathrm{ULCI}=.88, \Delta \mathrm{R}^{2}=.002$, and significantly moderated by living alone, $B=.32$, $S E=.15, p=.037, \mathrm{LLCI}=.04$, ULCI 
Table 3. Stepwise Regression Results Predicting Psychological and Social Outcomes from Outside Home Modality Use ( $\mathrm{N}=1475)$

\begin{tabular}{|c|c|c|c|c|c|c|c|c|}
\hline \multirow[b]{3}{*}{ Face-to-face } & \multicolumn{2}{|c|}{ Loneliness } & \multicolumn{2}{|c|}{$\begin{array}{l}\text { Social } \\
\text { Needs Met }\end{array}$} & \multicolumn{2}{|c|}{$\begin{array}{c}\text { Maintenance } \\
\text { Difficulties }\end{array}$} & \multicolumn{2}{|c|}{ Stress } \\
\hline & $\underline{b}$ & $\underline{\mathrm{SE}}$ & $\underline{b}$ & $\underline{\mathrm{SE}}$ & $\underline{b}$ & $\underline{\mathrm{SE}}$ & $\underline{b}$ & $\underline{\mathrm{SE}}$ \\
\hline & -.24 & .06 & .24 & .06 & -.21 & .06 & -.17 & .06 \\
\hline Online gaming & .26 & .07 & & & .26 & .07 & .19 & .08 \\
\hline Email & -.19 & .07 & & & & & -.14 & .06 \\
\hline Voice call & -.26 & -.11 & & & & & -.36 & .11 \\
\hline Video chat & .15 & .07 & & & .22 & .06 & & \\
\hline $\begin{array}{l}\text { Social media posting/ } \\
\text { commenting/sharing }\end{array}$ & .18 & .07 & & & & & .10 & .02 \\
\hline Texting & & & & & & & .32 & .10 \\
\hline$\Delta \mathrm{R}$-squared & $\bar{L}$ & .05 & - & .02 & & .04 & & .06 \\
\hline Male & -.16 & .06 & .12 & .06 & -.04 & .06 & -.30 & .06 \\
\hline Trans \& Nonbinary & .63 & .37 & -.59 & .34 & .67 & .36 & .34 & .37 \\
\hline Latinx & .23 & .11 & -.20 & .11 & .09 & .11 & .30 & .12 \\
\hline Black & -.27 & .10 & .28 & .09 & -.32 & .10 & -.15 & .10 \\
\hline Asian American & .15 & .14 & -.11 & .13 & .09 & .14 & .11 & .15 \\
\hline Native American & -.44 & .43 & .40 & .40 & -.64 & .42 & -.25 & .44 \\
\hline Pacific Islander & .04 & 1.13 & -.88 & .99 & 1.35 & 1.12 & -.15 & 1.15 \\
\hline Mixed Race & -.17 & .17 & .02 & .16 & .02 & .17 & .28 & .17 \\
\hline Education & .00 & .02 & .01 & .02 & .02 & .02 & .02 & .02 \\
\hline Income & -.00 & .01 & .00 & .01 & .00 & .01 & -.03 & .01 \\
\hline Sheltered in place & .78 & .10 & -.42 & .10 & .48 & .10 & .58 & .10 \\
\hline Romantic relationship & -.24 & .07 & .25 & .07 & -.19 & .07 & -.22 & .07 \\
\hline Live alone & -.07 & .09 & -.10 & .08 & .12 & .09 & -.35 & .09 \\
\hline Employed & .25 & .06 & .01 & .06 & .26 & .06 & .35 & .06 \\
\hline $\mathrm{R}^{2}$ & & .07 & & .05 & & .04 & & .08 \\
\hline
\end{tabular}

Notes. Reference groups were female, white, and non-Latinx for sex, race, and ethnicity respectively. People currently in a romantic relationship, who lived alone, and were employed were coded 1 . Bold $p<.01$

$=.62, \Delta \mathrm{R}^{2}=.003$. The association between $\mathrm{FtF}$ and loneliness was more negative for individuals who were SIP and living alone, compared to those who were not SIP or lived with others. The relationship between getting one's social needs met and FtF communication was moderated by SIP, $B=-.52$, SE $=.23, p=.021$, LLCI $=$ $-.96, \mathrm{ULCI}=-.08, \Delta \mathrm{R}^{2}=.004$. The association between FtF and getting needs met was more positive for those who were SIP. Finally, age moderated the association between FtF communication and stress, $B=-.013, S E=.003, p=.001$, LLCI $=-.020$, $\mathrm{ULCI}=-.007, \Delta \mathrm{R}^{2}=.009$. The negative association between stress and FtF communication was significant for middle-aged adults ( 49 yrs.) and older adults (68 yrs.), but not young adults (29 yrs.).

The second set of moderations explored using email to communicate with those outside the home. The relationship between email and loneliness was mod- 
erated by age, $B=-.0133, S E=.0028, p=.0000, \mathrm{LLCI}=-.019, \mathrm{ULCI}=-.008, \Delta \mathrm{R}^{2}=.002$. Results suggested that using email was associated with less loneliness for middle aged ( 49 yrs.) and older adults ( 68 yrs.); however, among young adults ( $29 \mathrm{yrs}$.) the use of email was associated with more loneliness.

The final set of moderations explored the use of social media. The association between loneliness and social media use was moderated by being in a romantic relationship, $B=.10, S E=.04, p=.012$, LLCI $=.02$, $\mathrm{ULCI}=.17, \Delta \mathrm{R}^{2}=.004$. Results suggested that while those in a romantic relationship were less lonely in general, the positive association between social media use and loneliness was stronger for those in a romantic relationship. The association between stress and social media use was also moderated by being in a romantic relationship, $B=.09, S E=.04, p=$ $.019, \mathrm{LLCI}=.015, \mathrm{ULCI}=.170, \Delta \mathrm{R}^{2}=.004$. Similar to the results of loneliness, using social media was associated with greater stress for all individuals, but for those in a romantic relationship that association was stronger.

\section{Discussion}

Polls by the Kaiser Family Foundation (2020) and the US Census Bureau (Fowers \& Wan, 2020) reported that nearly half of Americans said that the pandemic has harmed their mental health. Although COVID-19-related stressors directly (e.g., loss of employment) and indirectly (e.g., fear of infection) undoubtedly contributed to diminished mental health, the loss of frequency and variety of FtF interactions may have also negatively affected mental health and well-being (Moore et al., 2020; van Bavel et al., 2020). The present investigation identified the prevalence of ICT use during the SIP period of the COVID-19 pandemic and identified the associations among various modalities and social and mental health. What follows is a brief discussion of both the theoretical and practical implications of these findings.

On a theoretical level, the findings from this study suggest that the richness of a medium does not ensure social connection, despite the increase in social cues. More specifically, while MRT (Daft \& Lengel, 1984) would predict that video chat would be the most socially rewarding modality, the present investigation found this not to be the case; those who used video chat were lonelier and had greater relationship maintenance difficulties than those who did not, consistent with similar results for loneliness in previous research (Hall, 2020). There are several possible reasons for this. Referred to as "Zoom fatigue" (Wiederhold, 2020), video chat may require a high level of social energy expenditure (Hall, 2020), rendering video calls draining. Technical issues that reduce synchrony or make conversation difficult during video chat may disrupt the flow of conversation (Wiederhold, 2020). The ability to multi-task during voice calls suggests another source of discomfort during video chat: the voice caller can carry their conversation with them as they continue on with other activities, while video chatting requires more attention and eye contact, while allowing for less physical mobility. The specific context of loss of FtF contact for many may also exacerbate this finding, further demonstrating the limitations of MRT from March to May of 2020.

In regard to the media choice literature, the results regarding the effects of video chat also push back against the claim that modalities closely approximating FtF communication can help individuals get their social needs met. During the SIP 
period of the pandemic, many Americans perceived that there was considerable pressure to use video chat as a replacement for FtF interactions for both work and social gatherings (Andrews, 2020). However, a lack of familiarity with video chat platforms (Ishii et al., 2019) and the embodied reminders of an absent loved one on screen (Neustaedter \& Greenberg, 2012) may exacerbate, rather than alleviate, loneliness. This suggests that richer media used as a substitute, rather than a supplement, for FtF interaction may make people feel worse about the lack of $\mathrm{FtF}$ contact. As the research on video chat is scant, further research is necessary to understand the best explanation for these negative effects.

The present investigation has practical implications for sociality and (a lack of) compliance with social distancing measures during the COVID-19 pandemic. Alarmingly, technology appears to have failed to adequately meet many Americans' social needs. For respondents using technology to keep in touch with friends and family outside the home, $28 \%$ reported being lonely often or all of the time and only $36 \%$ reported getting their social needs met often or all of the time. Unmet social needs motivate people to seek FtF contact (Hall, 2020). Indeed, the Pew Research Center (2020a) found that roughly $60 \%$ of Americans would be willing to consider breaking social distancing guidelines to visit a close friend or family member in their home, despite the risks involved. In our study, those who were SIP were lonelier and more stressed compared to those who were not sheltering in place.

Furthermore, the results indicate that FtF contact was the only predictor of getting one's social needs met, and those who had FtF contact outside the home had fewer relational challenges than those who did not. Although FtF contact was associated with less loneliness and stress for all participants, it was particularly strongly associated with those outcomes for older adults, a finding confirmed in longitudinal research during the pandemic (Pew Research Center, 2020b). Given that older adults are at a greater risk of loneliness (Pinquart \& Sorenson, 2003), it is concerning that a lack of meaningful human contact through ICTs may put a vulnerable population at greater risk of catching the virus if they feel compelled to seek FtF contact.

On a more positive note, the present study offered some evidence certain ICTs can sustain well-being when FtF contact is not an option. In particular, phone calls were an important modality for communicating for $91 \%$ of respondents, and those who ranked calls as more important had fewer relationship maintenance challenges. Stepwise regression results suggested voice calls were associated with less stress and loneliness, supporting past research (Liu et al., 2019). This may be due to greater comfort and familiarity of phone calls. Participants ranked video chat's importance as similar to email-well below texting and voice calls. Ishii et al. (2019) argue that voice calls can be considered a richer medium due to immediate vocalic feedback and fewer technical issues related to video chat. Thus, voice calls may be viewed as comfortable, familiar, and, thus, a more satisfying form of communication.

In a somewhat unexpected result, email was also identified as a relationship-sustaining modality (see also Ruppel \& Burke, 2015). Participants who ranked email as more important reported less stress, and email use was associated with less stress and loneliness in stepwise regressions. Although the use of email 
within interpersonal relationships has declined in recent years (Hall, 2020), a preference for the medium suggests comfort with a technology influences its efficacy. Consider that the benefits of email were moderated by age. Middle aged (49 yrs.) and older adults (69 yrs.) reported less loneliness when using email than younger adults. By contrast, among young adults (29 yrs.), the use of email to stay in touch was associated with more loneliness. This may reflect a greater familiarity with email for personal contact for those who began using it 25 or more years ago when its adoption for relationship maintenance became widespread (Hall, 2020).

By comparison, two newer ICTs, online gaming and social media, were both associated with greater feelings of loneliness, confirming trends detected in a recent meta-analysis (Liu et al., 2019). Zhu (2020) suggests that while online gaming can allow for connection with others, the escapism may perpetuate feelings of loneliness when one is offline. In contrast to past research on social media use (Lui et al., 2019), the present investigation found social media use was related to loneliness and stress whether passive or active in form, consistent with recent work on the use of social media during the pandemic (Zhong et al., 2020). Furthermore, moderation analyses suggested that, compared to single adults, those who were in romantic relationships were more stressed and lonelier when using social media. Perhaps turning to social media when in a romantic relationship is a sign that individuals are not getting their social needs met in that relationship. However, this explanation is speculative without further evidence. In sum, social media and online gaming may be problematic means of alleviating - or may be a sign of - stress and loneliness brought about by the COVID-19 pandemic.

Finally, although texting was a very popular modality both in overall use $(90 \%)$ and in terms of rank order, it was unassociated with positive outcomes. This lack of benefit stands in contrast with past research (Lui et al., 2019). The single significant association with greater stress in stepwise regression results was inconsistent with the broader pattern of the lack of predictive value of texting. Because voice calls and texting co-occur with close relational partners (Liu \& Yang, 2016) and are both very popular, this association may be spurious.

\section{Limitations}

One limitation is the use of cross-sectional data. Because constructs were measured at only one time point, the direction of causality is unknown. It is possible that lonely and stressed individuals are more likely to use certain modalities (e.g., gaming, social media, video chat), while less lonely and stressed individuals use email and voice calls. We cannot conclude that voice calls and email are more effective than video chat and online gaming. Although modality use explained as much variation in mental and social health as did demographic characteristics and structural factors (e.g., SIP, employment), the overall amount of variance explained was relatively low $\left(R_{\text {range }}^{2}=.02-.08\right)$.

An additional limitation is reliance on one-item measures. Such measures were deemed appropriate for the present study to allow for a balance of internal and external validity. Using a brief survey allowed us to collect data from nearly 2,000 diverse individuals living throughout the US, over a few days during a pandemic. Cheung and Donnellan (2014) recommend using single-item measures to reduce participant burden, concluding that single-item measures can have sufficient criterion validity compared to multiple item measures. 


\section{Conclusion}

The results suggest no modalities approximate the social and psychological potency of FtF interaction and that MRT alone cannot explain the patterns of results, especially the contrasting results for video chat and voice calls. Although the benefits or harms of ICT use during the pandemic was partly dependent on access to important others and participant age, the strongest effects did not differ by these factors. Among the modalities, voice calls, and to lesser degree email, appear to have had distinct significance, in frequency, importance, and effect on well-being for Americans when keeping in touch with friends and family during the SIP period.

\section{References}

Andrews, T. M. (2020, March 30). We're all video chatting now. But some of us hate it. The Washington Post. https://www.washingtonpost.com/technology/2020/03/30/video-chat-zoom-skype-hangouts-hate-bad/

Baym, N. K. (2015). Personal connections in the digital age (2nd ed.). Malden, MA: Polity Press.

Caughlin, J. P., \& Sharabi, L. L. (2013). A communication interdependence perspective of close relationships: The connections between mediated and unmediated interactions matter. Journal of Communication, 63(5), 873-893. doi:10.1111/ jcom/12046

Cheung, F, \& Lucas, R. E. (2014). Assessing the validity of single-item life satisfaction measures: results from three large samples, Qual Life Res, 23, 2809-2818. doi: 10.1007/s11136-014-0726-4

Daft, R. L. \& Lengel, R. H. (1984). Information richness: A new approach to managerial behavior and organizational design. In L. L. Cummings \& B. M. Staw (Eds.), Research in organizational behavior (pp. 191-233). Homewood, IL: JAI Press.

Domahidi, E., Breuer, J., Kowert, R., Festl, R., \& Quandt, T. (2018). A longitudinal analysis of gaming-and non-gaming-related friendships and social support among social online game players. Media Psychology, 21(2), 288-307.

Duran, R. L., \& Kelly, L. (2017). Knapp's model of relational development in the digital age. Iowa Journal of Communication, 49, 22-45. https://doi.org/10.1080/1 $\underline{5213269.2016 .1257393}$

Eden, J. \& Veksler, A. E. (2016). Relational maintenance in the digital age: Implicit rules and multiple modalities. Communication Quarterly, 64(2), 119-144. doi:10 $.1080 / 01463373.2015 .1103279$

Fischer, C. S. (1992). America calling: A social history of the telephone to 1940. Berkeley, CA: University of California Press.

Fowers, A., \& Wan, W. (2020, May 26). A third of Americans now show symptoms of clinical anxiety or depression, Census Bureau finds amid coronavirus pandemic. The Washington Post. https://www.washingtonpost.com/ health/2020/05/26/americans-with-depression-anxiety-pandemic/

Hall, J. A. (2020). Relating through technology. Cambridge, UK: Cambridge University Press.

Hall, J. A., \& Merolla, A. (2020). Connecting everyday talk and time alone to global well-being. Human Communication Research, 46, 594-619. doi:10.1093/hcr/ hqz014 
Hayes, A. F. (2018). Introduction to mediation, moderation, and conditional process analysis: A regression-based approach ( $2^{\text {nd }} e d$.). NYC, NY: The Guilford Press.

Ishii, K., Lyons, M. M., \& Carr, S. A. (2019). Revisiting media richness theory for today and future. Human Behavior \& Emerging Technologies, 1(2), 124-131. doi:10.1002/hbe2.138

Kaiser Family Foundation (2020). The implications of COVID-19 for mental health and substance use. https://www.kff.org/coronavirus-covid-19/issue-brief/theimplications-of-covid-19-for-mental-health-and-substance-use/

Koeze, E. \& Popper, N. (2020, April 7). The virus has changed the way we internet. The New York Times. https://www.nytimes.com/interactive/2020/04/07/ technology/coronavirus-internet-use.html?action=click\&module=Editors $\% 20$ Picks\&pgtype=Homepage

Kushlev, K., \& Dunn, E. W. (2015). Checking email less frequently reduces stress. Computers in Human Behavior, 43, 220-228. doi:10.1016/j.chb.2014.11.005

Leary, M. R., \& Kelly, K. M. (2008). Belonging motivation. In M. R. Leary \& Rick H. Hoyle (Eds.), Handbook of individual differences in social behavior (pp. 400-409). NYC, NY: Guilford.

Liu, D., Baumeister, R. F., Yang, C. C., \& Hu, B. (2019). Digital communication media use and psychological well-being: A meta-analysis. Journal of Computer-Mediated Communication, 24(5), 259-273. Doi.10.1093/ccc/zmz013

Liu, D., \& Yang, C-C. (2016). Media niche of electronic communication channels in friendship: A meta-analysis. Journal of Computer-Mediated Communication, 21(6), 451-466. doi:10.1111/jcc4.12175

Minium, A. (2020, April 13). Americans are making more phone calls than ever before. Our Community Now. https://ourcommunitynow.com/news-tech/americansare-making-more-phone-calls-than-ever-before

Moore, R. C., Lee, A., Hancock, J. T., Halley, M., \& Linos, E. (2020). Experience with social distancing early in the COVID-19 pandemic in the United States: Implications for public health messaging. medRxiv preprint. doi:10.1101/2020.04.08.20057067

Neustaedter, C., \& Greenberg, S. (2012). Intimacy in long-distance relationships over video chat. In Proceedings of the SIGCHI Conference on Human Factors in Computing Systems (CHI '12). ACM in NYC, NY, 753-762. doi:10.1145/2207676.2207785

Pew Research Center (2020a, April 30). From virtual parties to ordering food, how Americans are using the internet during COVID-19. https://www.pewresearch.org/fact-tank/2020/04/30/from-virtual-parties-to-ordering-food-howamericans-are-using-the-internet-during-covid-19/

Pew Research Center (2020b, June 16). Experiences with the COVID-19 outbreak can vary for Americans of different ages. https://www.pewresearch.org/facttank/2020/06/16/experiences-with-the-covid-19-outbreak-can-vary-for-americans-of-different-ages/

Pinquart, M. \& Sorensen, S. (2003). Risk factor for loneliness in adulthood and old age: A meta-analysis. In S. P. Shohov (Ed.), Advances in psychology research (vol. 19, pp. 111-143). Hauppage, NY: Nova Science.

Reinecke, L., Vorderer, P., \& Knop, K. (2014). Entertainment 2.0? The role of intrinsic and extrinsic need satisfaction for the enjoyment of Facebook use. Journal of Communication, 64(3), 417-438. doi:10.1111/jcom.12099 
Ruppel, E. K., \& Burke, T. J. (2015). Complementary channel use and the role of social competence. Journal of Computer-Mediated Communication, 20(1), 37-51. doi: $10.1111 /$ jcc 4.12091

Ryff, C. D., \& Keyes, C. L. M. (1995). The structure of psychological well-being revisited. Journal of Personality and Social Psychology, 69(4), 719-727. doi: 10.1037//0022-3514.69.4.719.

Sarkisian, N., \& Gerstel, N. (2016). Does singlehood isolate or integrate? Examining the link between marital status and ties to kin, friends, and neighbors. Journal of Social and Personal Relationships, 33(3), 361-384. doi:10.1177/0265407515597564

Sanderson, G. M., \& Dunn, E. W. (2014). Social interactions and well-being: The surprising power of weak ties. Personality and Social Psychology Bulletin, 40(7), 910-922. doi:10.1177/0146167214529799

Sheldon, K. M., Abad, N., \& Hinsch, C. (2011). A two-process view of Facebook use and relatedness need-satisfaction: Disconnection drives use, and connection rewards it. Journal of Personality and Social Psychology, 100(4), 766-775. doi:10.1037/a0022407

Sprecher, S. (2014). Initial interactions online-text, online-audio, online-video, or face-to-face: Effects of modality on liking, closeness, and other interpersonal outcomes. Computers in Human Behavior, 31, 190-197. doi:10.1016/j. chb.2013.10.029

Stepanikova, I., Nie, N. H., \& He, X. (2010). Time on the Internet at home, loneliness, and life satisfaction: Evidence from panel time-diary data. Computers in Human Behavior, 26(3), 329-338. doi:10.1016/j.chb.2009.11.002

Tillema, T., Dijst, M., \& Schwanen, T. (2010). Face-to-face and electronic communications in maintaining social networks: The influence of geographical and relational distance and of information content. New Media $\mathcal{E}$ Society, 12(6) 965983. doi:10.1177/146144480953011

Tong, S. T., \& Walther, J. B. (2015). The confirmation and disconfirmation of expectancies in computer-mediated communication. Communication Research, 42(2), 186-212. doi:10.1177/0093650212466257

van Bavel, J. J., Baicker, K., et al. (2020). Using social and behavioural science to support COVID-19 pandemic response. Nature Human Behaviour, 4, 460-471. doi:10.1038/s41562-020-0884-z

van den Berg, P. E. W., Arentze, T. A., \& Timmermans, H. J. P. (2012). New ICTs and social interaction: Modeling communication frequency and communication mode choice. New Media \& Society, 14(6), 987-1003. doi:10.1177.146144812437518

van der Horst, M., \& Coffe, H. (2012). How friendship network characteristics influence subjective well-being. Social Indicators Research, 107(3), 509-529. doi:10.1007/s11205-011-9861-2

Vlahovic, T. A., Roberts, S., Dunbar, R. (2012). Effects of duration and laughter on subjective happiness within different modes of communication. Journal of Computer-Mediated Communication, 17(4), 436-450. doi:10.1111/j.10836101.2012.01584.x

Walther, J. B. (2010). Computer-mediated communication. In C. R. Berger, M. E. Roloff, \& D. R. Roskos-Ewoldsen (Eds.), Handbook of communication science (2nd ed.) (pp. 489-505) Los Angeles, CA: Sage. 
Walther, J. B. (2011). Theories of computer-mediated communication and interpersonal relations. In M. L. Knapp \& J. A. Daly (Eds.), Sage handbook of interpersonal communication (4th ed.) (pp. 443-480). Los Angeles, CA: Sage.

Wiederhold, B. K. (2020). Connecting through technology during the Coronavirus disease 2019 pandemic: Avoiding "zoom fatigue." Cyberpsychology, Behavior, and Social Networking, 23(7), 437-9. doi:10.1098/cyber.2020.29188.bkw

Zhong, B., Huang, Y., \& Liu, Q. (2020). Mental health toll from the coronavirus: Social media usage reveals Wuhan residents' depression and secondary trauma in the COVID-19 outbreak. Computers in Human Behavior, 114, 1-10. doi:10.1016/j.chb.2020.106524

Zhu, L. (2020). The psychology behind video games during COVID-19 pandemic: A case study of Animal Crossing: New Horizons. Human Behavior \& Emerging Technology. 1-3. doi:10.1002/hbe2.221 